\title{
How medical school debt shapes the health workforce
}

\author{
— Cite as: CMAJ 2018 July 23;190:E894-5. doi: 10.1503/cmaj.109-5607
}

Posted on cmajnews.com on July 5, 2018.

W hat would it mean for doctors and patients if medical students didn't have to pay tuition? Philanthropists Dr. P. Roy and Diana Vagelos think debt-free education would allow more students to enter highneed areas, including primary care, research and pediatrics.

That's their motivation for providing $\$ 250$ million to the Columbia University Irving Medical Center in New York, \$150 million of which will fund scholarships. About $20 \%$ of medical students, those with the highest financial needs, won't have to pay tuition, and another $30 \%$ will receive smaller scholarships.

The initiative could make medical school more accessible for students from low-income backgrounds, in addition to encouraging lower-paying specialty choices, according to Rishad Khan, a thirdyear medical student at the Schulich School of Medicine and Dentistry, who is coleading a study of the demographics of Canadian medical students. Although many Canadian medical schools have scholarships to cover tuition, they are available only to a few students per program each year, said Khan.

Research shows that tuition fees affect socioeconomic patterns within applicant pools. Canada "had a very natural experiment" when Ontario deregulated tuition fees for professional programs in the late 1990s, said Khan. An analysis found that the sharp rise in tuition resulted in fewer applications to programs like medicine and law from students whose parents didn't have graduate degrees.

In addition, said Khan, "we know from Canadian data that students with higher debt loads are more likely to cite financial considerations as having a major impact

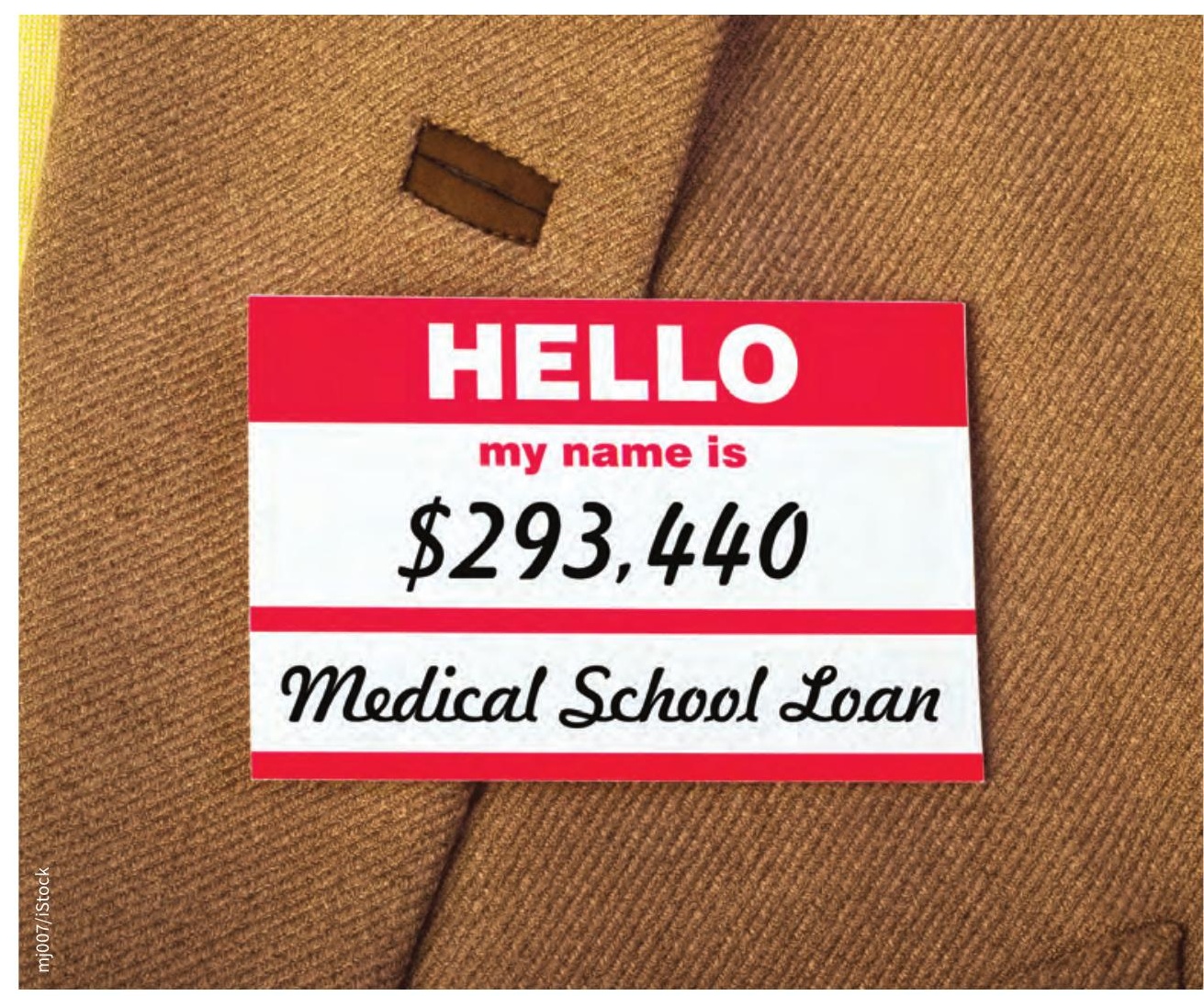

Many medical students cite huge debt loads as a factor when choosing a specialty.

on their practice location and specialty." Other Canadian research shows that lower debt loads after medical school is associated with higher likelihood of entering family medicine.

Debt is likely to be an even bigger factor in specialty decisions for medical students in the United States. Tuition at the more expensive medical programs in Canada is around \$25 000 a year. Many private US medical schools cost more than twice as much.

Dr. Jim Dahle, an emergency physician in Utah and founder of The White Coat Investor, said that "there is a certain subsegment of medical students who literally cannot afford to be pediatricians." Students are finishing residency with $\$ 500000$ in debt in some cases, and pediatricians make $\$ 150000$ to $\$ 200000$ a year, he said.

"Everybody is not going to turn around and go, 'Yeah, I want to do pediatrics in some inner city [if debt-free],' but there's a significant percentage of physicians who would, and it's the money that keeps them from doing it," he said.

Stephanie Smith, president-elect of the Canadian Federation of Medical Students, thinks less worry about debt could also improve mental health for students and residents. "I think the financial pres- 
sure does have a significant impact on people's burnout," she said. "If you're not getting much time to yourself, and you're feeling pretty exhausted, it can help if you know you can take the weekend off and go somewhere nice." Leisure activities that can help counter burnout, like yoga classes or dinner with friends, are luxuries many medical students and residents don't feel they can afford.

Research supports a link between debt and medical student wellbeing. A survey of more than 3000 medical students in the US found that students with higher debt loads than their peers reported more incidences of feeling callous toward others, were more likely to choose specialties based on income, were less interested in practising primary care or in underserved locations, and were more likely to question their choice to become a physician.

Slashing medical school tuition is possible for many universities in Canada and
US, said Dahle, especially those with major endowments. Tuition is so high because schools know students are willing to pay, he said. Students are "not thinking of the return on their investment," Dahle said. "This is a dream they've had since they were in middle school, so they go, 'What does it take? Everybody else is borrowing $\$ 400000$. I will borrow $\$ 400000$."”

Wendy Glauser, Toronto, Ont. 